\title{
Phase I Clinical, Pharmacokinetic, and Pharmacodynamic Study of KOS-862 (Epothilone D) in Patients with Advanced Solid Tumors and Lymphoma
}

\author{
Jason Konner ${ }^{1}$, Rachel N. Grisham ${ }^{1}$, Jae Park ${ }^{1}$, Owen A. O'Connor ${ }^{2}$, Gillian Cropp ${ }^{3}$, Robert \\ Johnson ${ }^{4}$, Alison L. Hannah ${ }^{3}$, Martee L. Hensley ${ }^{1}$, Paul Sabbatini ${ }^{1}$, Svetlana Miranov ${ }^{5}$, \\ Samuel Danishefsky ${ }^{6}$, David Hyman ${ }^{1}$, David R. Spriggs ${ }^{1}$, Jakob Dupont ${ }^{7}$, and Carol \\ Aghajanian $^{1}$ \\ ${ }^{1}$ Department of Medicine, Memorial Sloan-Kettering Cancer Center, New York, NY, USA \\ ${ }^{2}$ New York University Cancer Institute, New York, NY, USA \\ ${ }^{3}$ Nereus Pharmaceuticals, Inc., San Diego, CA, USA \\ ${ }^{4}$ Aeolian Biomed, Lafayette, CA, USA \\ ${ }^{5}$ Department of Radiology, Memorial Sloan-Kettering Cancer Center, New York, NY, USA \\ ${ }^{6}$ Department of Molecular Pharmacology and Chemistry, Memorial Sloan-Kettering Cancer \\ Center, New York, NY, USA \\ ${ }^{7}$ Genentech, Inc., 1 DNA Way, South San Francisco, CA, USA
}

\begin{abstract}
Purpose-To determine the maximum tolerated dose and safety of the epothilone, KOS-862, in patients with advanced solid tumors or lymphoma.
\end{abstract}

Patients and Methods-Patients were treated weekly for 3 out of 4 weeks (Schedule A) or 2 out of 3 weeks (Schedule B) with KOS-862 $\left(16-120 \mathrm{mg} / \mathrm{m}^{2}\right)$. Pharmacokinetic (PK) sampling was performed during cycles 1 and 2; pharmacodynamic (PD) assessment for microtubule bundle formation (MTBF) was performed after the 1st dose, only at or above $100 \mathrm{mg} / \mathrm{m}^{2}$.

Results-Thirty-two patients were enrolled, and twenty-nine completed $\geq 1$ cycle of therapy. Dose limiting toxicity [DLT] was observed at $120 \mathrm{mg} / \mathrm{m}^{2}$. PK data were linear from 16 to 100 $\mathrm{mg} / \mathrm{m}^{2}$, with proportional increases in mean $\mathrm{C}_{\max }$ and $\mathrm{AUC}_{\text {tot }}$ as a function of dose. Full PK analysis (mean $\pm \mathrm{SD}$ ) at $100 \mathrm{mg} / \mathrm{m}^{2}$ revealed the following: half-life $\left(\mathrm{t}_{1} / 2\right)=9.1 \pm 2.2$ hours; volume of distribution $\left(\mathrm{V}_{\mathrm{Z}}\right)=119 \pm 41 \mathrm{~L} / \mathrm{m}^{2}$; clearance $(\mathrm{CL})=9.3 \pm 3.2 \mathrm{~L} / \mathrm{h} / \mathrm{m}^{2}$. MTBF $(\mathrm{n}=9)$ was seen in $40 \%$ of PBMCs within 1 hour and in $15 \%$ of PBMC at 24-hours post infusion at $100 \mathrm{mg} / \mathrm{m}^{2}$. Tumor shrinkage ( $\mathrm{n}=2$, lymphoma), stable disease $>3$ months $(\mathrm{n}=5$, renal, prostate, oropharynx, cholangiocarcinoma, and Hodgkin lymphoma), and tumor marker reductions ( $\mathrm{n}=1$, colorectal cancer/CEA) were observed.

Correspondence to: Jason Konner, MD, Gynecologic Medical Oncology Service, Department of Medicine, Memorial SloanKettering Cancer Center, 1275 York Avenue, New York, NY 10021, Tel: 212 639-8151, Fax: 212-717-3272, konnerj@ mskcc.org. Conflict of Interest Statement: The authors have no conflict of interest to declare. 
Conclusion-KOS-862 was well tolerated with manageable toxicity, favorable PK profile, and the suggestion of clinical activity. The maximum tolerated dose was determined to be $100 \mathrm{mg} / \mathrm{m}^{2}$ weekly 3-on/1-off. MTBF can be demonstrated in PBMCs of patients exposed to KOS-862.

\section{Keywords}

epothilone; KOS-862; epothilone D; Solid tumors; lymphoma

\section{INTRODUCTION}

Agents that target microtubules have potent cytotoxic effects, and are among the most commonly prescribed anti-cancer therapies. The taxanes (paclitaxel and docetaxel) bind and stabilize tubulin, preventing depolymerization of microtubules, resulting in $\mathrm{G}_{2} / \mathrm{M}$ phase arrest and induction of apoptosis [1-3]. Taxanes have well-documented activity in several malignancies including breast, ovarian, and lung cancer. Despite this activity, acquired drug resistance is frequently encountered through over-expression of drug efflux protein Pglycoprotein or mutation of $\beta$-tubulin [4-6]. In addition, many tumor types are inherently resistant to taxanes.

The epothilones represent a class of non-taxane drugs capable of stabilizing the tubulin structure by binding to $\beta$-tubulin in a manner similar to paclitaxel, causing cell cycle arrest at the $\mathrm{G}_{2} / \mathrm{M}$ transition [7-9]. Although taxanes and epothilones occupy the same binding site on $\beta$-tubulin, electron crystallography and molecular modeling suggest that epothilones do not share a common pharmacophore with taxanes [10]. The epothilones were first discovered in the early 1990's as naturally occurring macrolides [11]. Epothilone A and epothilone B are secondary metabolites isolated from the myxobacterium Sorangium cellulosum. In addition, numerous epothilone analogs have been synthesized. Multiple epothilones have entered clinical trials, including ixabepilone, patupilone, BMS-310705, KOS-1584,ZK-EPO and KOS-862 [12-16]. Thus far ixabepilone is the only Food and Drug Administration (FDA) approved epothilone. Ixabepilone is approved as monotherapy for the treatment of locally advanced or metastatic breast cancer resistant or refractory to anthracyclines, taxanes, and capecitabine; additionally, it is indicated in combination with capecitabine in patients with locally advanced or metastatic breast cancer that is resistant to anthracyclines and taxanes, or resistant to taxanes with contraindications to anthracycline therapy [14].

Epothilone D (KOS-862) (Figure 1), is a more potent microtubule stabilizer in vitro than epothilone A or B [17]. In vitro, KOS-862 (Epothilone D) has shown potent cytotoxicity in a panel of human tumor cell lines, with similar potency to paclitaxel. It also showed a definite advantage over paclitaxel in drug-resistant cell lines, and retained its cytotoxicity against a multidrug resistant cell line over-expressing P-glycoprotein $[18,19]$. In vivo, antitumor efficacy has been observed in both paclitaxel-sensitive and -resistant xenografts, as well as certain multidrug resistant xenografts including a doxorubin-resistant CCRF-CEM leukemic cell xenograft $[18,20,21]$.

This phase I study was designed to determine the maximum tolerated dose (MTD), the pharmacokinetics (PK), and the safety profile of KOS-862 administered as a weekly 
infusion for 3 of 4 (Schedule A) or for 2 of 3 weeks (Schedule B). The study was also designed to measure microtubule bundle formation (MTBF) in Peripheral Blood Mononuclear Cells (PBMCs) of treated patients as a pharmacodynamic (PD) endpoint.

\section{PATIENTS AND METHODS}

\section{Patient Selection}

Eligible patients had an advanced solid tumor or lymphoma with no known curative therapy. Patients also required: measurable or clinically evaluable disease, a Karnofsky Performance Status (KPS) $\geq 60$, AST and ALT $\leq 2.5$ times the upper limit of normal ( $\leq 5$ times for patients with liver metastases), bilirubin $\leq 2.0 \mathrm{mg} / \mathrm{dL}$ (unless Gilbert's disease), serum creatinine $\leq 1.5 \mathrm{mg} / \mathrm{dL}$, absolute neutrophil count $\geq 1,500 / \mathrm{mL}$, platelet count $\geq 75,000 / \mathrm{mL}$. and hemoglobin $\geq 8.0 \mathrm{~g} / \mathrm{dL}$. Exclusion criteria included: (1) pre-existing peripheral neuropathy (PN) $\geq$ grade 2; (2) HIV positive patients; or (3) previous chemotherapy or radiation therapy within 4 weeks of study drug administration. Prior treatment with a taxane was permitted but not required. Memorial Sloan-Kettering's Institutional Review Board approved the study, and written informed consent was obtained from enrolled patients.

\section{Clinical Study Design}

This was a single-center, open-label, dose-escalation study. KOS-862 was administered as an intravenous (IV) infusion over 90 minutes on days 1,8 , and 15 of a 28-day cycle (Schedule A). The starting dose was $16 \mathrm{mg} / \mathrm{m}^{2}$ for Schedule A. This dose was set at onethird the toxic-dose-low in the dog and administered weekly for 3 weeks out of 4 . Dose escalation was performed using an NCI-FDA accelerated design scheme [18]. Doses were doubled in successive 3-person cohorts until either 1 instance of DLT or 2 instances of drugrelated grade 2 toxicity (except for nausea/vomiting, fatigue, anorexia, alopecia, or anemia) were observed, at which time 3 additional patients were added to the cohort. Thereafter, the dose escalation followed a modified Fibonacci sequence (i.e., dose increments of 67\%, 50\%, $40 \%, 33 \%$, and 25\%). A second schedule (Schedule B) tested drug administration every 2 weeks out of 3 (day 1 and 8 of a 21 day cycle). Schedule B dose level was fixed at the MTD observed in Schedule A $\left(100 \mathrm{mg} / \mathrm{m}^{2}\right)$. Both schedules used a fixed time of administration (90 minutes) for all doses. No intra-patient dose escalation was allowed.

The DLT was defined as either: (1) $\geq$ grade 3 non-hematologic toxicities except fever, chills, or flu-like symptoms; (2) $\geq$ grade 3 thrombocytopenia; (3) grade 4 neutropenia $>5$ days; (4) febrile neutropenia during cycle 1 of therapy; or (5) re-treatment delay $>3$ weeks.

When at least 2 of 6 patients in any given dose cohort experienced a DLT, there was to be no further dose escalation and this dose level was called the maximum administrable dose (MAD). The dose level immediately below the MAD was identified as the maximum tolerated dose (MTD). Additional patients (up to 10) were then enrolled at the MTD to gain additional information regarding the toxicity profile and PK parameters.

Prior to study drug infusion, the first 6 patients were premedicated with antihistamines per Regimen A (loratadine $10 \mathrm{mg}$ PO and famotidine $20 \mathrm{mg}$ PO or equivalently dosed substitute) given at least 30 minutes prior to treatment. The remainder of patients were 
premedicated with antihistamines and low-dose steroids per Regimen B $\left(\mathrm{H}_{1}\right.$ and $\mathrm{H}_{2}$ blockers as above and either methylprednisolone $40 \mathrm{mg}$ IV or dexamethasone $10 \mathrm{mg}$ IV) at least 30 minutes prior to treatment.

The primary objective of the study was to determine MTD and DLT for each of the 2 schedules. Secondary objectives were to define safety and plasma PK profile, and to assess PD sampling and potential antitumor activity.

\section{Treatment Assessment}

Baseline assessment included a physical examination, review of systems, complete blood count (CBC) with differential, hepatic and renal function tests, coagulation parameters, urinalysis, 12-lead electrocardiogram (ECG), and chest x-ray. Negative pregnancy test was required for women of childbearing potential. Tumor measurements with CT scan or MRI were performed at baseline. During the study, history, physical examination, weight, vital signs, KPS, CBC, and blood chemistries were monitored weekly. Urinalysis was evaluated every 3 weeks. Additional safety monitoring included neurological evaluation by physical examination following infusions, and ECG pre- and post-infusion. Radiographic tumor response assessment was performed at least every 2 cycles (every 6-8 weeks), with response assessed according to the WHO RESICT criteria.

\section{Pharmacokinetic Study}

Blood samples were collected on Day 1 of cycles 1 and 2 (schedules A and B), and on Day 15 (schedule A only): a $7 \mathrm{~mL}$ sample of whole blood was obtained pre-infusion, at 30 and 90 minutes into the infusion, and post-infusion at 5, 15, 30, 45, and 60 minutes; and at 2, 4, $6,8,24$, and 27 hours.

Plasma samples were split into 2 cryovials and stored at $-70^{\circ} \mathrm{C}$. The maximum concentration $\left(\mathrm{C}_{\max }\right)$, time to maximum serum concentration $\left(\mathrm{T}_{\max }\right)$, area under the concentration-time curve (AUC), clearance, steady-state volume of distribution $\left(\mathrm{V}_{\mathrm{ss}}\right)$, and apparent half-life $\left(\mathrm{t}_{1 / 2}\right)$ were determined.

\section{Pharmacodynamic Study}

MTBF in interphase cells was assessed as an indicator of increased polymerization. PD sampling (percent MTBF in PBMC) was performed on Cycle 1:Day 1 for doses $\geq 100$ $\mathrm{mg} / \mathrm{m}^{2}$. PBMC's were obtained in Cycle 1 at pre-infusion, end of infusion, 1, 4, and 24 hours post infusion (days 1 and 15 for schedule A; days 1 and 22 for schedule B).

\section{Analytical Method}

Plasma concentrations of KOS-862 were measured using a validated, automated HPLC/MS method. In brief, patient plasma samples, quality control samples, and calibrators were thawed in an ice bath and then vortex mixed. Aliquots $(100 \mu \mathrm{L})$ of samples were pipetted into $1.2 \mathrm{~mL}$ titer tubes, $800 \mu \mathrm{L}$ internal standard (IS, Epothilone C, concentration $25 \mathrm{ng} / \mathrm{mL}$ in acetonitrile) was added, and the samples were then transferred to an auto tube holding plate according to a generated sequence. 
Extraction was performed with the TOMTEC Quadra 96 TM using a solid phase extraction method. Prior to loading samples, the SPE cartridges (Versaplate, C18, $50 \mathrm{mg}$ ) were conditioned with $600 \mu \mathrm{L}$ methanol and with $700 \mu \mathrm{L}$ of $1.0 \%$ trifluoroacetic acid (TFA) in water. After loading the samples, cartridges were washed with $2100 \mu \mathrm{L}$ water and then 1050 $\mu \mathrm{L} 10 / 90$ (v/v) methanol/water. Samples were eluted with $600 \mu \mathrm{L}$ methanol and the eluent evaporated to dryness at $60^{\circ} \mathrm{C}$ with nitrogen in a Zymark Turbovap 96 .

Samples were reconstituted in $400 \mu \mathrm{L}$ of $50: 50(\mathrm{v} / \mathrm{v})$ methanol/water, vortex mixed and transferred to injection vials. Samples were injected into a Perkin Elmer Series 200 with a Keystone Hypersil C18 column $(30 \times 4.6,3.0 \mu \mathrm{m})$. Mobile phase was methanol:1.0\% formic acid in water (70:30, v/v).

A Perkin Elmer Sciex API 3000 with turbo ion spray source was used to analyze the effluent from the chromatographic column. The analytes were detected using selected reaction monitoring in positive ion mode. Fragmentation of the precursor ions was achieved using nitrogen as collision gas and collision energy $\left(\mathrm{E}_{\mathrm{lab}}\right)$ of $35 \mathrm{eV}$ for KOS-862 and Epothilone C. The mass transitions monitored were $\mathrm{m} / \mathrm{z} 492 \rightarrow 304$ for KOS-862 and $478 \rightarrow 290$ for Epothilone C, respectively. Analyte quantitation was done by peak area ratio using a linear equation weighted $1 / \mathrm{Y}$.

The intra-assay and inter-assay precision (average $\% \mathrm{CV}$ ) at the lower limit of quantitation was $3.6 \%$ and $8.9 \%$, respectively.

\section{RESULTS}

\section{Patient Characteristics and Treatment Administration}

Thirty-two patients were registered to the study, with 29 patients receiving at least one dose of study drug. Demographics and disease characteristics of patients treated on Schedules A and $\mathrm{B}$ are listed on Table 1. The median age of patients was 55 years (range, 25-77), the male-to-female ratio was 15:17, and the median KPS was 80\% (range, 70-100). The median number of prior chemotherapeutic, hormonal, or immune regimens was 5 (range, 2-9).

For Schedule A, cohorts of three to six patients were treated at each dose level until the MTD was defined. Once the MTD was identified, this dose level was expanded to 10 patients to better define the tolerability and pharmacokinetics of the dose. Schedule B was started at the MTD defined by Schedule A.

Of the 32 patients enrolled in the trial, 22 received Schedule A (intravenous dose administered every 3 weeks out of 4 over 90 minutes) and 10 patients received Schedule B (intravenous dosing every week $2 / 3$ via the same constant time infusion). Doses ranged during Schedule A from $16-120 \mathrm{mg} / \mathrm{m}^{2}$; all patients received $100 \mathrm{mg} / \mathrm{m}^{2}$ on Schedule B.

All 22 patients who entered Schedule A completed the first study period, Cycle 1 Day 1; eighteen patients completed both study periods in Cycle 1; 15 patients continued to complete Cycle 2 Day 1 . All patients were included in the data analysis. 
During the conduct of the Protocol, several patients were dose reduced from the initial dose level to one dose level lower. Two patients initially at dose level $100 \mathrm{mg} / \mathrm{m}^{2}$ were deescalated to $75 \mathrm{mg} / \mathrm{m}^{2}$ in Cycle 3 (PK sampling was not affected); one patient initially treated at $120 \mathrm{mg} / \mathrm{m}^{2}$ was de-escalated to $100 \mathrm{mg} / \mathrm{m}^{2}$; this affected PK sampling on Cycle 2/Day 1. For the pharmacokinetic analysis this patient was included in a cohort based on the actual dose administered rather than in the original cohort to which she was accrued

Overall, the median number of cycles administered was 2 (range, 1-6). Twenty-six of 32 patients $(81 \%)$ came off of study due to progression of disease; 3 patients $(9 \%)$ were removed from the study due to DLT events. A summary of the dose escalation and dosing schedule for each cohort of patients is provided in Table 2.

\section{Pharmacokinetics}

Compartment-independent PK analysis demonstrated no evidence of nonlinear PK at the doses and administration schedules studied, although the data suggested a tendency toward nonlinearity of systemic exposure and maximal plasma concentration at the highest dose administered. KOS-862 plasma concentration curves showed a rapid distribution phase followed by a slower elimination phase with no appreciable change of slope as the dose increased (Figure 2A and 2B). The plasma concentration curve measured at repeated dosing at weekly intervals (Schedule A) also demonstrated a stationary PK with negligible changes (Figure 3). Based on these data, it was concluded that there is conservation of both slope and elimination phase indicating stationary kinetics when KOS-862 was administered on Schedule A.

The $t_{1 / 2}$ on Schedule A was $9.0 \pm 2.4$ hours; while the $t_{1 / 2}$ was $7.5 \pm 1.3$ hours on Schedule B. Total systemic clearance was $9.69 \pm 3.8 \mathrm{~L} / \mathrm{h} / \mathrm{m}^{2}$ and $7.45 \pm 2.4 \mathrm{~L} / \mathrm{h} / \mathrm{m}^{2}$ for Schedule A and B respectively. The $\mathrm{V}_{\mathrm{ss}}$ was $76.53 \pm 28.0 \mathrm{~L} / \mathrm{m}^{2}$ or $148.28 \pm 68.1 \mathrm{~L}$ for Schedule A, and $48.1 \pm$ $13 \mathrm{~L} / \mathrm{m}^{2}$ or $85.67 \pm 27.8 \mathrm{~L}$ for Schedule B. The $\mathrm{V}_{\mathrm{ss}}$ was $70.84 \pm 28.04 \mathrm{~L} / \mathrm{m}^{2}$ or $135 \pm 66.41$ $\mathrm{L}$ for all patients, regardless of schedule. Systemic exposure (as measured by $\mathrm{AUC}_{\mathrm{tot}}$ ) increased as a linear function of dose $\left(\mathrm{R}^{2}=0.998\right)$ between 16 and $100 \mathrm{mg} / \mathrm{m}^{2}$ (Figure 4 ), and appeared to demonstrate some deviation from linearity at $120 \mathrm{mg} / \mathrm{m}^{2}$ on Schedule A. For the dose of $100 \mathrm{mg} / \mathrm{m}^{2}$, the maximal plasma concentration peaked at the end of the infusion in the majority of patients, at $3688 \pm 1053 \mathrm{ng} / \mathrm{mL}$ for Schedule A and $4825 \pm 1360 \mathrm{ng} / \mathrm{mL}$ for Schedule B.

Intra-patient variability (based on a comparison of the PK of individual patients given doses 7 days apart) was negligible. Inter-patient variation within cohorts was sometimes significant, in several cases with 3-fold variation between patients in systemic exposure. Gender differences in this protocol were confined to the $\mathrm{V}_{\mathrm{ss}}$ and apparent volume of distribution during the terminal half-life $\left(\mathrm{V}_{\mathrm{Z}}\right)$ when uncorrected for BSA. Females showed significantly smaller $\mathrm{V}_{\mathrm{ss}}$ than males (111.51 \pm 48.04 vs. $159.28 \pm 73.67 \mathrm{~L}$, respectively), and lower apparent volume of distribution during the terminal half-life $\left(\mathrm{V}_{\mathrm{Z}}\right)(182.98 \pm 83.10 \mathrm{vs}$. $240.87 \pm 108.73 \mathrm{~L}$, respectively). The difference disappeared when the $\mathrm{V}_{\mathrm{Z}}$ and $\mathrm{V}_{\mathrm{ss}}$ were corrected for BSA. No gender differences were seen for $\mathrm{AUC}_{\mathrm{tot}}, \mathrm{t}_{1 / 2}$, or clearance. 


\section{Pharmacodynamics}

KOS-862 induced MTBF in PBMCs in a dose-and time-dependent manner that failed to correlate with $\mathrm{AUC}_{\mathrm{tot}}, \mathrm{C}_{\max }, \mathrm{t}_{1 / 2}$, and clearance. Although it is not possible to actually measure the concentration of drug in the effect compartment, the PK/PD modeling indicated that KOS-862 at 900 to $1900 \mathrm{ng} / \mathrm{mL}$ in the tumor would result in MTBF in greater than 35\% of the cells.

\section{DLT and MTD}

There was one DLT in 1 of 10 patients at $100 \mathrm{mg} / \mathrm{m}^{2}$ in Schedule A (grade 2 peripheral sensory neuropathy), and 2 of 10 patients at $100 \mathrm{mg} / \mathrm{m}^{2}$ in Schedule B (grade 2 peripheral sensory neuropathy and visual hallucination). None was experienced by more than one patient, and only one patient required a dose reduction to $75 \mathrm{mg} / \mathrm{m}^{2}$. Two cases of peripheral sensory neuropathy occurred after $2^{\text {nd }}$ infusion, and resolved within 7-8 days. Visual hallucination occurred in one patient after Cycle 1, infusion 1 in Schedule B; the dose was reduced to $75 \mathrm{mg} / \mathrm{m}^{2}$ for subsequent cycles with no recurrence of DLT.

At $120 \mathrm{mg} / \mathrm{m}^{2}, 3$ DLTs occurred in 2 of 2 patients in Schedule A. One patient had a transient visual hallucination ( $<1$ minute) requiring no action on study medication; a second patient had severe NVD with dehydration. This patient was dose reduced to $100 \mathrm{mg} / \mathrm{m}^{2}$ and rechallenged without recurrence of this toxicity. Based on these DLTs, $100 \mathrm{mg} / \mathrm{m}^{2}$ on Schedule A was considered the MTD and the recommended dose for Phase II studies.

Possible hypersensitivity reactions (HSR) were observed in 5 patients. Initially, patients received premedication Regimen A (antihistamines only), and 2 of 6 (33\%) experienced a possible HSR. Subsequently, all patients were converted to Regimen B (antihistamines with low-dose steroids) and the incidence of these reactions occurred in 3 of 26 (12\%).

\section{Other Toxicities}

All patients in the study had at least one adverse event (AE). In Schedule A, the most frequent treatment-related AEs included fatigue (59\%), peripheral sensory neuropathy $(41 \%)$, diarrhea (36\%), and constipation (32\%). Treatment-related AEs that were somewhat more frequent in the higher dose groups included diarrhea, nausea, skin and subcutaneous tissue disorders, peripheral sensory neuropathy, insomnia, and exertional dyspnea. In Schedule B, the most frequently reported treatment-related AEs were fatigue (70\%), peripheral sensory neuropathy (50\%), insomnia (50\%), and anemia (40\%).

Six of 18 evaluable patients (33\%) in Schedule A and 5 of 9 evaluable patients (55\%) in Schedule B experienced a decrease in their KPS, that was possibly treatment related. Six of 22 patients (27\%) in Schedule A experienced weight loss $>5 \%$ from baseline $(6.8-15 \%)$, most (4 out of 6 patients) occurring at $100 \mathrm{mg} / \mathrm{m}^{2}$. Two of $10(20 \%)$ patients in Schedule B experienced weight loss of $>5 \%$ from baseline $(9.3-11.8 \%)$ during the first 2 weeks of starting therapy.

In Schedule A, 8 patients (38\%) among 22 experienced serious adverse events (SAEs), including 2 deaths; both occurred during the 30-day follow-up period and neither was considered related to the study drug. The causes of death were respiratory failure and failure 
to thrive. Of the 18 SAEs experienced by these 8 patients, 11 (61\%) were considered not related to study drug; 3 (17\%) were considered unlikely related to study drug, including pain in limb, muscle weakness, and ventricular arrhythmia; and 4 (22\%) were considered possibly or probably related to study medication, including dehydration, diarrhea, and syncope, all experienced by the same patient. Four patients were removed from the study because of AEs, including diarrhea, nausea, hypotrichosis, peripheral sensory neuropathy, syncope, and ventricular arrhythmia.

In Schedule B, there were no deaths among the 10 patients treated or during the 30-day follow-up period. Five patients (50\%) experienced a total of 7 SAEs, including anemia, small bowel obstruction, cellulitis, dehydration, failure to thrive, and hemoptysis. With the exception of anemia, no SAEs occurred in more than one patient. Of the 7 SAEs, 5 (71\%) were considered not related to study drug; one (14\%), small-bowel obstruction, was considered unlikely related; and one (14\%), anemia, was considered possibly related. Two patients (20\%) were discontinued because of AEs, which were hemoptysis, anemia, anorexia, dehydration, failure to thrive, and vomiting. Toxicities ( $\geq$ grade 3 ) related to study drug are listed in Table 3.

With both schedules of administration, marginal decreases in white blood cell count, absolute neutrophil count, and hemoglobin were observed during treatment. No clinically significant effects on platelet counts, total bilirubin, or AST were observed.

Increases in systolic blood pressure $\geq 25 \mathrm{mmHg}$ during infusions were observed in $22 \%$ of patients. These increases were transient and probably reflected hypersensitivity to the Cremophor® in the drug formulation.

ECGs were performed on 17 patients prior to each infusion and at one hour after completion, in addition to those performed at baseline and termination. $\mathrm{QT}_{\mathrm{c}}$ prolongation (> $450 \mathrm{msec}$ at 1-hour post-dose of $>60 \mathrm{msec}$ increases from pre-dose to 1 hour post-dose) was observed in 10 of these 17 patients (58\%). All of these episodes returned to a normal range by the subsequent infusion. None of the patients developed $\mathrm{QT}_{\mathrm{c}}>500 \mathrm{msec}$, and there was no associated occurrence of malignant arrhythmia or sudden death.

Neurological examinations revealed treatment-emergent sensory neuropathy (hands/feet) to be the most frequent neurotoxicity, and it was dose limiting (grade 2) in 2 patients at 100 $\mathrm{mg} / \mathrm{m}^{2}$. In Schedule A, treatment-emergent peripheral neuropathy (PN) was reported in $36 \%$ of patients, $41 \%$ of whom experienced numbness and tingling. These findings were more frequent among the patients treated at $100 \mathrm{mg} / \mathrm{m}^{2}(60 \% \mathrm{PN})$. In Schedule B, $80 \%$ of patients had treatment-emergent PN, which consisted mostly of numbness (50\%) and tingling (80\%). Pain, burning, and motor findings were less frequent in both schedules.

Non-sensory neurotoxicity ranged in severity, and was clearly dose-dependent. While patients at lower doses experienced weakness upon standing, those at higher doses $\left(\geq 100 \mathrm{mg} / \mathrm{m}^{2}\right.$ ) developed frank ataxia. Similarly, while cognitive/perceptual abnormalities (confusion, dizziness, blurry vision) occurred at lower doses, visual hallucinations were seen at higher doses. Neurotoxicity typically reached maximum severity 1-3 days following infusion, with resolution over the ensuing 1-5 days. 


\section{Antitumor Activity}

No patient in Schedule A or Schedule B experienced a response by WHO-RECIST criteria. Tumor shrinkage was observed in two patients with diffuse large B-cell (27\% decrease in target lesions after Cycle 2 at $100 \mathrm{mg} / \mathrm{m}^{2}$ in Schedule A) and Hodgkin lymphoma (18\% decrease in target lesions and a CR of non-target lesions after Cycle 3 at $100 \mathrm{mg} / \mathrm{m}^{2}$ in Schedule B).

In addition, $\mathrm{SD} \geq 3$ months was seen in patients with renal ( $\mathrm{n}=1$, papillary subtype), prostate $(\mathrm{n}=1)$, oropharynx cancer $(\mathrm{n}=1)$, cholangiocarcinoma $(\mathrm{n}=1)$, and Hodgkin lymphoma $(\mathrm{n}=1)$. All of these outcomes were observed in the $100 \mathrm{mg} / \mathrm{m}^{2}$ group. One patient with colorectal cancer experienced a 37\% decrease in tumor marker level (CEA) after 3 cycles of therapy. This patient was considered to have had progressive disease at study termination by radiographic criteria, although the patient's condition remained clinically stable 2 months following discontinuation of therapy.

\section{DISCUSSION}

In this report, we present the results of the initial phase I dose-escalation study of the epothilone KOS-862 (Epothilone D) in patients with advanced solid tumors or lymphoma. As with other epothilones, the most prominent toxicities appeared to be neurologic and gastrointestinal.

The primary DLT was a reversible neurotoxicity, which was dose related. Although a limited number of patients received more than 2 cycles, the toxicities were not cumulative. The DLT of KOS-862 appears to be schedule-independent. Other phase I evaluations have also identified neurotoxicity as dose-limiting [22, 23].

Transient, mild QT ${ }_{\mathrm{c}}$ prolongation ( $>450 \mathrm{msec}$ but $<500 \mathrm{msec}$ ) was observed in 10 of the 17 patients $(58 \%)$ when measured pre- and one hour post-infusion. All of these episodes were isolated events with no accompanying symptoms, and the $\mathrm{QT}_{\mathrm{c}}$ intervals returned to a normal range by the next dose. No ECG abnormality was associated with any occurrence of malignant arrhythmia or sudden death. However, for future studies, a routine monitoring of ECGs is recommended, and persistent $\mathrm{QT}_{\mathrm{c}}$ elevation > $500 \mathrm{msec}$ or associated symptoms should warrant further evaluation.

Based on the toxicity profile at the MTD, the recommended phase II dose is $100 \mathrm{mg} / \mathrm{m}^{2}$ weekly 3 weeks out of every 4 . Toxicities at this dose level that were not dose-limiting included: fatigue (50\%), reversible peripheral neuropathy (hypoesthesia 40\%; paresthesia $30 \%$ ), dizziness (30\%), nausea/vomiting/diarrhea (30\%) not requiring prophylaxis, and anemia (mild). This dose and schedule carries an overall weekly dose intensity of $75 \mathrm{mg} / \mathrm{m}^{2} /$ week, nearly double the weekly dose intensity compared with the 4 other phase I schedules evaluated: $120 \mathrm{mg} / \mathrm{m}^{2}$ as a single dose every 3 weeks (40 mg/m²/week) [23]; $40 \mathrm{mg} / \mathrm{m}^{2}$ over 3 consecutive days every 3 weeks ( $40 \mathrm{mg} / \mathrm{m}^{2} /$ week) [23]; $4 \mathrm{mg} /$ hour $\times 24$ hours every 2 weeks (48 mg/week) [22]; and $1 \mathrm{mg} /$ hour $\times 72$ hours every 2 weeks (36 mg/week) [22]. Weekly, non-protracted dosing used in this study appears preferable since it is better tolerated, easy to administer, and achieves higher systemic exposures. 
Although preclinical data demonstrating that a 6-hour infusion $\left(\mathrm{V}_{\mathrm{ss}} \sim 500 \mathrm{ng} / \mathrm{mL}\right)$ in the mouse xenograft model demonstrated optimal antitumor efficacy [18], phase I trials investigating continuous infusion schedules (24-hour and 72-hour continuous infusion every 2 weeks) did not result in greater antitumor effect [22]. The weekly study schedule of 3 weeks out of 4 weeks from this clinical trial, therefore, was advanced into phase II clinical trials.

In this study, KOS-862 demonstrated modest signs of antitumor activity. While no formal PR or CR was achieved by WHO-RECIST criteria, tumor shrinkage was observed in 2 patients with diffuse large B-cell and Hodgkin lymphoma. In addition, SD ( $\geq 3$ months) was seen in renal, prostate, andoropharyngeal cancer, cholangiocarcinoma, and Hodgkin lymphoma. In addition, a 37\% decline in CEA was observed in a patient with colorectal cancer.

KOS-862 displayed linear kinetics over all studied doses. The drug achieved a $t_{1 / 2}$ approximating 10 hours. Microtubule bundle formation in PBMCs is a marker of the ability of a microtubule-stabilizing drug to bind to its target in vivo and induce tubulin polymerization, however data is lacking as to whether MTBF can be directly correlated with anti-tumor activity [24]. MTBF was found to be both a time- and dose-dependent PD endpoint, though no correlation with $\mathrm{AUC}_{\text {tot }}$ was found. Bundle formation was observed at all post-infusion time points. $\mathrm{PK} / \mathrm{PD}$ analysis supports $1000 \mathrm{ng} / \mathrm{mL}$ as the target intratumoral drug concentration for optimal biological effect (using $\%$ microtubule bundling) in humans.

In conclusion, KOS-862 was generally well tolerated in this patient population with a favorable PK profile and the suggestion of clinical activity in patients with lymphoma. KOS-1584 is a synthetic analogue of KOS-862. This second generation epothilone was designed to have a longer half-life, larger volume of distribution, less toxicity, more potency and higher solubility than KOS-862 [25]. The first-in-human study of KOS-1584 showed a favorable toxicity profile and early evidence of activity [25]. Further development of KOS-862 was therefore halted at the phase II level in favor of additional development of KOS-1584. The lessons learned from this phase I study of KOS-862 presented here were vital to our understanding of the toxicities associated with epothilones and have led to further development and refinement of this class of drugs.

Recently, epothilone B (Ixabepilone) was approved by the FDA for treatment of metastatic breast cancer, and the clinical niche to be filled by epothilones will likely expand. There are now multiple phase II trials completed with various epothilone analogs in cancers in which taxanes are known to be effective (breast [26-28], endometrial [28], ovarian [29], lung [30], head \& neck [31], prostate [32, 33], germ cell tumor [34], pancreas [35], gastric adenocarcinoma [36]). There are also completed phase II trials with various epothilone analogs in cancer in which taxanes are not known to be effective (colorectal [37], renal cell [31, 38], NHL [39]). In addition, there are completed and in-progress clinical trials examining epothilones in combination with capecitabine, estramustine, gemcitabine, carboplatin, trastuzumab, liposomal doxorubicin, irinotecan, and mitoxantrone [40-45]. 


\section{Acknowledgments}

Supported in part by funds granted by *The American Society of Clinical Oncology Career Development Awards (JD), and by The Damon Runyon-Lilly Clinical Investigator Award (JD). OAO was supported in part by a Leukemia and Lymphoma Society Research Scholar Award.

\section{REFERENCES}

1. Schiff PB, Fant J, Horwitz SB. Promotion of microtubule assembly in vitro by taxol. Nature. 1979; 277(5698):665-667. [PubMed: 423966]

2. Yvon AM, Wadsworth P, Jordan MA. Taxol suppresses dynamics of individual microtubules in living human tumor cells. Mol Biol Cell. 1999; 10(4):947-959. [PubMed: 10198049]

3. Altmann KH, Wartmann M, O'Reilly T. Epothilones and related structures--a new class of microtubule inhibitors with potent in vivo antitumor activity. Biochim Biophys Acta. 2000; 1470(3):M79-M91. [PubMed: 10799747]

4. Horwitz SB, et al. Taxol: mechanisms of action and resistance. J Natl Cancer Inst Monogr. 1993; (15):55-61. [PubMed: 7912530]

5. Jachez B, Nordmann R, Loor F. Restoration of taxol sensitivity of multidrug-resistant cells by the cyclosporine SDZ PSC 833 and the cyclopeptolide SDZ 280-446. J Natl Cancer Inst. 1993; 85(6): 478-483. [PubMed: 8095304]

6. Nogales E, et al. Structure of tubulin at 6.5 A and location of the taxol-binding site. Nature. 1995; 375(6530):424-427. [PubMed: 7760939]

7. Rowinsky EK, et al. Clinical toxicities encountered with paclitaxel (Taxol). Semin Oncol. 1993; 20(4 Suppl 3):1-15. [PubMed: 8102012]

8. Rose WC. Taxol: a review of its preclinical in vivo antitumor activity. Anticancer Drugs. 1992; 3(4):311-321. [PubMed: 1358264]

9. Kowalski RJ, Giannakakou P, Hamel E. Activities of the microtubule-stabilizing agents epothilones A and B with purified tubulin and in cells resistant to paclitaxel (Taxol(R)). J Biol Chem. 1997; 272(4):2534-2541. [PubMed: 8999970]

10. Nettles JH, et al. The binding mode of epothilone A on alpha,beta-tubulin by electron crystallography. Science. 2004; 305(5685):866-869. [PubMed: 15297674]

11. Gerth K, et al. Epothilons A and B: antifungal and cytotoxic compounds from Sorangium cellulosum (Myxobacteria). Production, physico-chemical and biological properties. J Antibiot (Tokyo). 1996; 49(6):560-563. [PubMed: 8698639]

12. Lee $\mathrm{SH}$, et al. Epothilones induce human colon cancer SW620 cell apoptosis via the tubulin polymerization independent activation of the nuclear factor-kappaB/IkappaB kinase signal pathway. Mol Cancer Ther. 2007; 6(10):2786-2797. [PubMed: 17938270]

13. Cheng KL, Bradley T, Budman DR. Novel microtubule-targeting agents - the epothilones. Biologics. 2008; 2(4):789-811. [PubMed: 19707459]

14. Trivedi M, et al. Epothilones: a novel class of microtubule-stabilizing drugs for the treatment of cancer. Future Oncol. 2008; 4(4):483-500. [PubMed: 18684060]

15. Harrison M, Swanton C. Epothilones and new analogues of the microtubule modulators in taxaneresistant disease. Expert Opin Investig Drugs. 2008; 17(4):523-546.

16. Goodin S, Kane MP, Rubin EH. Epothilones: mechanism of action and biologic activity. J Clin Oncol. 2004; 22(10):2015-2025. [PubMed: 15143095]

17. Nicolaou KC, et al. Synthesis of epothilones A and B in solid and solution phase. Nature. 1997; 387(6630):268-272. [PubMed: 9153390]

18. Chou TC, et al. Desoxyepothilone B is curative against human tumor xenografts that are refractory to paclitaxel. Proc Natl Acad Sci U S A. 1998; 95(26):15798-15802. [PubMed: 9861050]

19. Skehan P, et al. New colorimetric cytotoxicity assay for anticancer-drug screening. J Natl Cancer Inst. 1990; 82(13):1107-1112. [PubMed: 2359136]

20. Chou TC, et al. The synthesis, discovery, and development of a highly promising class of microtubule stabilization agents: curative effects of desoxyepothilones $\mathrm{B}$ and $\mathrm{F}$ against human 
tumor xenografts in nude mice. Proc Natl Acad Sci U S A. 2001; 98(14):8113-8118. [PubMed: 11438750]

21. Chou TC, et al. Desoxyepothilone B: an efficacious microtubule-targeted antitumor agent with a promising in vivo profile relative to epothilone B. Proc Natl Acad Sci U S A. 1998; 95(16):96429647. [PubMed: 9689134]

22. Holen K. Phase I study using continuous intravenous (CI) KOS-862 (Epothilone D) in patients with solid tumors. Proc Am Soc Clin Oncol. 2004 abstract 2024.

23. Piro L. KOS-862 (epothilone D): a comparison of two schedules in patients with advanced malignancies. Proc Am Soc Clin Oncol. 2003; 22 (abstract 539).

24. Arnold D, et al. Weekly administration of sagopilone (ZK-EPO), a fully synthetic epothilone, in patients with refractory solid tumours: results of a phase I trial. Br J Cancer. 2009; 101(8):12411247. [PubMed: 19773753]

25. Lam ET, et al. Phase I dose escalation study of KOS-1584, a novel epothilone, in patients with advanced solid tumors. Cancer Chemother Pharmacol. 2011

26. Perez EA, et al. Efficacy and safety of ixabepilone (BMS-247550) in a phase II study of patients with advanced breast cancer resistant to an anthracycline, a taxane, and capecitabine. J Clin Oncol. 2007; 25(23):3407-3414. [PubMed: 17606974]

27. Roche H, et al. Phase II clinical trial of ixabepilone (BMS-247550), an epothilone B analog, as first-line therapy in patients with metastatic breast cancer previously treated with anthracycline chemotherapy. J Clin Oncol. 2007; 25(23):3415-3420. [PubMed: 17606972]

28. Chen T, molina A, Moore S, et al. Epothilone B analog (BMS-247550) at the recommended phase II dose (RPTD) in patients (pts) with gynecologic (gyn) and breast cancers. Proc Am Soc Clin Oncol. 2004; 22(2115a)

29. Smit W, Sufliarsky J, Spanik S, et al. Phase I/II dose-escalation trial of patupilone every 3 weeks in patients with relapsed/refractory ovarain cancer. Proc Am Soc Clin Oncol. 2005; 23(5056a)

30. Vansteenkiste J, et al. Phase II clinical trial of the epothilone B analog, ixabepilone, in patients with non small-cell lung cancer whose tumors have failed first-line platinum-based chemotherapy. J Clin Oncol. 2007; 25(23):3448-3455. [PubMed: 17606973]

31. Burtness B, Goldwasser M, Axelrod R, et al. A randomized phase II study of BMS-247550 (ixabepilone) given daily $\times 5$ days eevry 3 weeks or weekly in patients with metastatic or recurrent squamous cell cancer of the head and neck. Proc Am Soc Clin Oncol. 2006; 24(5532a)

32. Altmann KH. Recent developments in the chemical biology of epothilones. Curr Pharm Des. 2005; 11(13):1595-1613. [PubMed: 15892665]

33. Beer TM, et al. Phase II study of KOS-862 in patients with metastatic androgen independent prostate cancer previously treated with docetaxel. Invest New Drugs. 2007; 25(6):565-570. [PubMed: 17618407]

34. Feldman DR, et al. Phase II trial of ixabepilone in patients with cisplatin-refractory germ cell tumors. Invest New Drugs. 2007; 25(5):487-490. [PubMed: 17520176]

35. Whitehead RP, et al. A Phase II trial of epothilone B analogue BMS-247550 (NSC \#710428) ixabepilone, in patients with advanced pancreas cancer: a Southwest Oncology Group study. Invest New Drugs. 2006; 24(6):515-520. [PubMed: 16699973]

36. Ajani JA, et al. A multi-center phase II study of BMS-247550 (Ixabepilone) by two schedules in patients with metastatic gastric adenocarcinoma previously treated with a taxane. Invest $\mathrm{New}$ Drugs. 2006; 24(5):441-446. [PubMed: 16586011]

37. Eng C, et al. A phase II trial of the epothilone B analog, BMS-247550, in patients with previously treated advanced colorectal cancer. Ann Oncol. 2004; 15(6):928-932. [PubMed: 15151950]

38. Posadas EM, et al. A phase II study of ixabepilone (BMS-247550) in metastatic renal-cell carcinoma. Cancer Biol Ther. 2007; 6(4):490-493. [PubMed: 17457044]

39. Smith S, Pro B, Van Besien K, et al. A phase II study of epothilone B analog BMS-247550 (NSC 710428 ) in patients with relapsed aggresive non-Hodgkin's lymphomas. Proc Am Soc Clin Oncol. 2005; 23(6625a)

40. Galsky MD, et al. Multi-institutional randomized phase II trial of the epothilone B analog ixabepilone (BMS-247550) with or without estramustine phosphate in patients with progressive castrate metastatic prostate cancer. J Clin Oncol. 2005; 23(7):1439-1446. [PubMed: 15735119] 
41. Hensley ML, et al. A phase I trial of BMS-247550 (NSC\# 710428) and gemcitabine in patients with advanced solid tumors. Invest New Drugs. 2007; 25(4):335-341. [PubMed: 17364235]

42. Forster M, et al. A phase $\mathrm{Ib}$ and pharmacokinetic trial of patupilone combined with carboplatin in patients with advanced cancer. Clin Cancer Res. 2007; 13(14):4178-4184. [PubMed: 17634546]

43. Plummer R. Phase I and pharmakokinetic study of BMS-247-550 in combination with carboplatin in patients with advanced solid malignancies. Proc Am Soc Clin Oncol. 2002 abstract 2125.

44. Faivre S. Phase I study of ixabepilone given every other week in combination with irinotecan in patients with advanced malignancies. Proc Am Soc Clin Oncol. 2004 abstract 2051.

45. Wojtowicz M. Phase I dose-escalation trial investigating the saftey and tolerability of EPO906 plus estramustine in patients with advanced cancer. Proc Am Soc Clin Oncol. 2004 abstract 4623. 


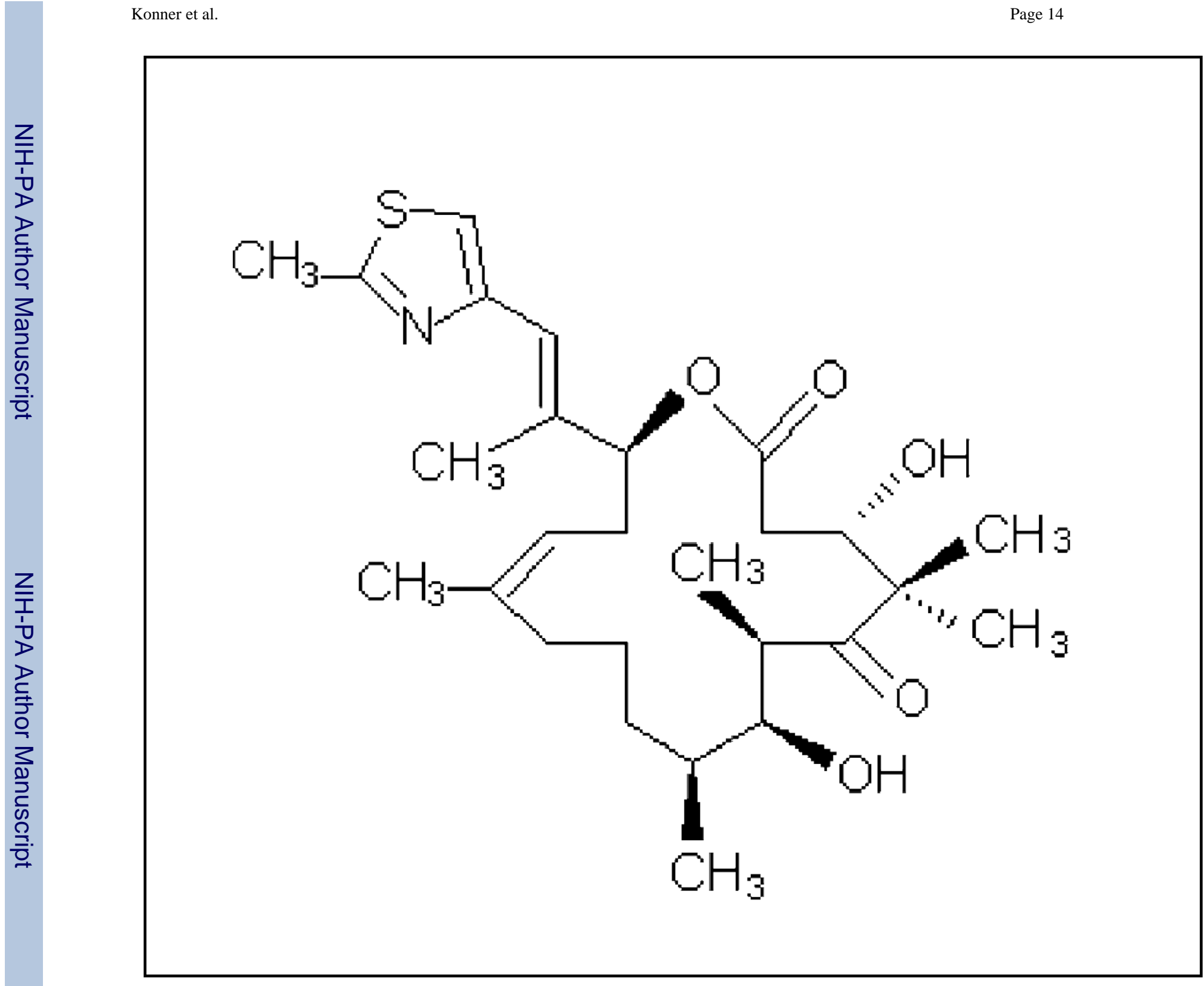

Figure 1. Chemical Structure of Epothilone D 
A

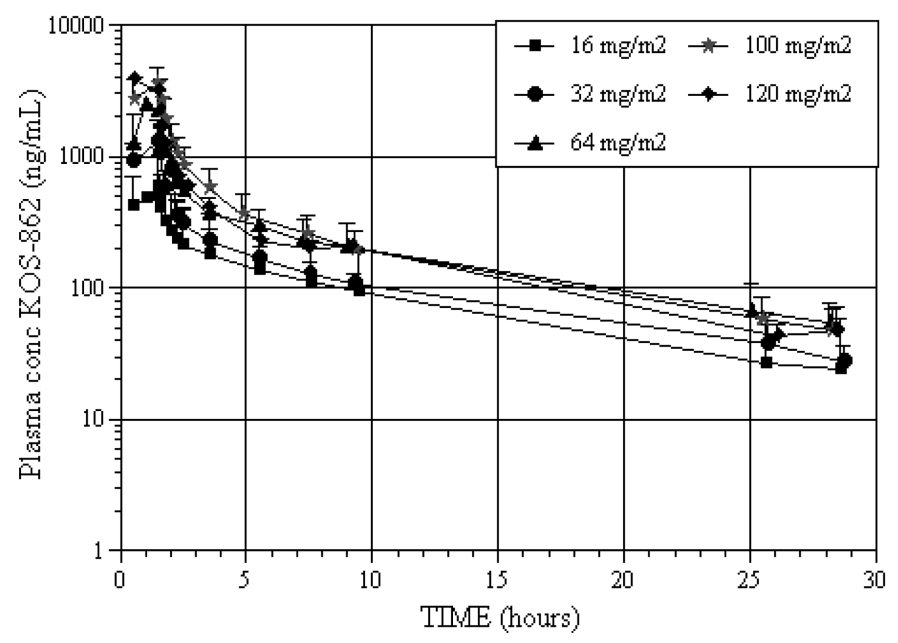

B

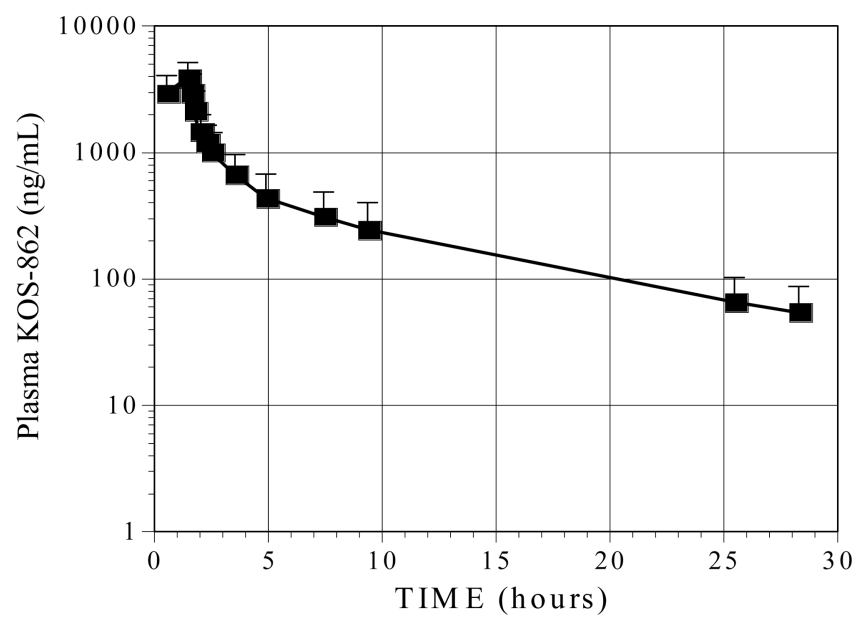

Figure 2. Plasma Concentration : Time Curves

A : Plasma concentration : time curves for the five cohorts collected during two cycles of treatments show rapid distributive phase and slower elimination phase. Mean curves remain essentially parallel in the termina phase, indicating that the half-life for

KOS-862 does not change with dose. $2 \mathrm{~B}$ : Plasma concentration :time curves for patients at the maximum tolerated dose $100 \mathrm{mg} / \mathrm{m}^{2}$ on Schedule A and B. $\mathrm{T}_{1 / 2} 9.1 \pm 2.2$ hours; $\mathrm{AUC}_{\text {tot }} 12093 \pm 4730 \mathrm{ng} * \mathrm{~h} / \mathrm{mL} \mathrm{Cmax} 4037+1277 \mathrm{ng} / \mathrm{mL}$; Clearance $17.5 \pm 5.7 \mathrm{~L} / \mathrm{hr} \mathrm{Vz} 119 \pm 41 \mathrm{~L} / \mathrm{m}^{2} ; \mathrm{PK}$ is dose independent $N=14$ patients on Schedules A and B (mean $\left.\pm \mathrm{SD}\right)$ 


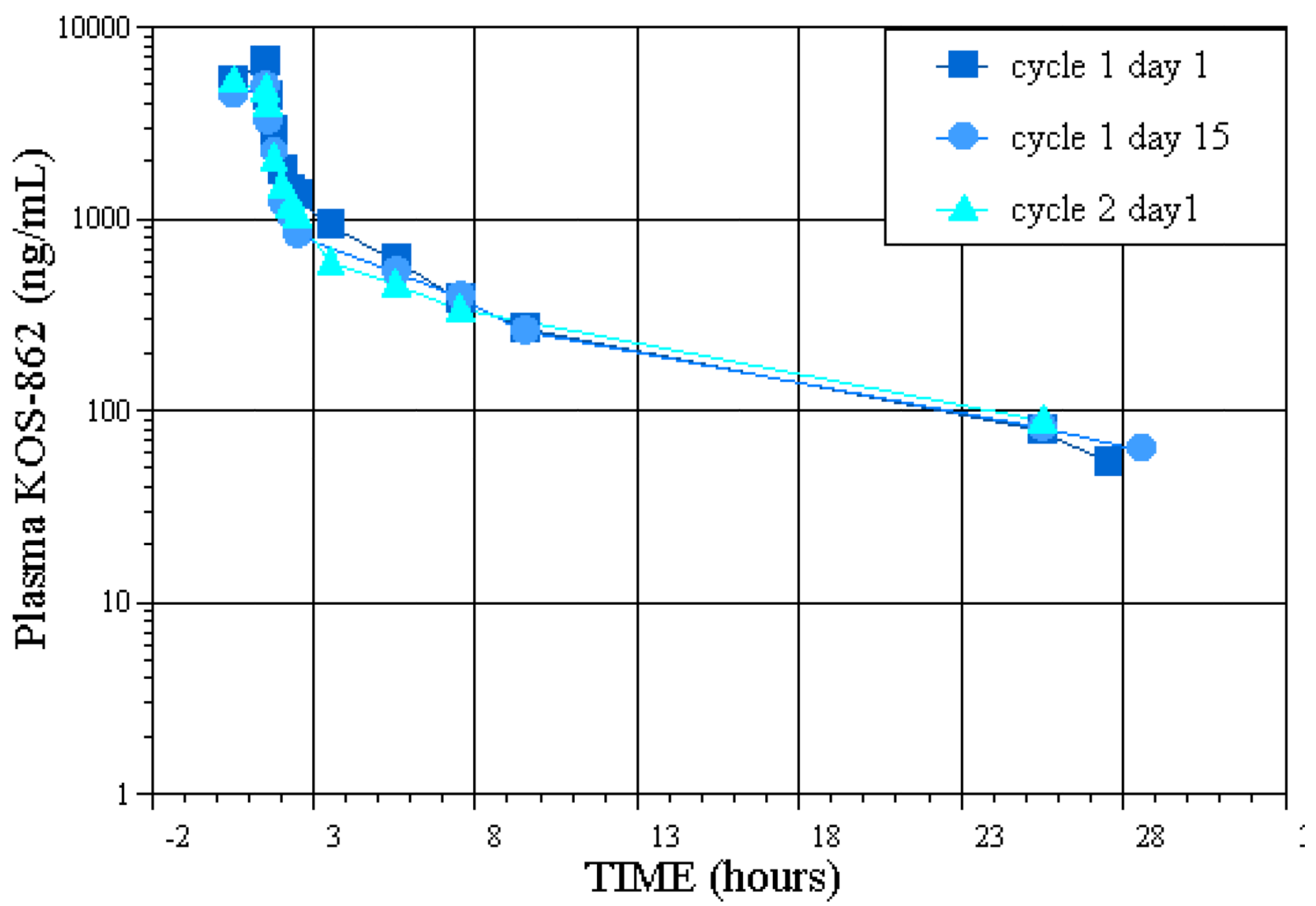

Figure 3. Plasma concentration: time profiles for three different days at $100 \mathrm{mg} / \mathrm{m}^{2}$. This graph demonstrates a stationary PK with negligible changes upon repeated dosing at weekly intervals 


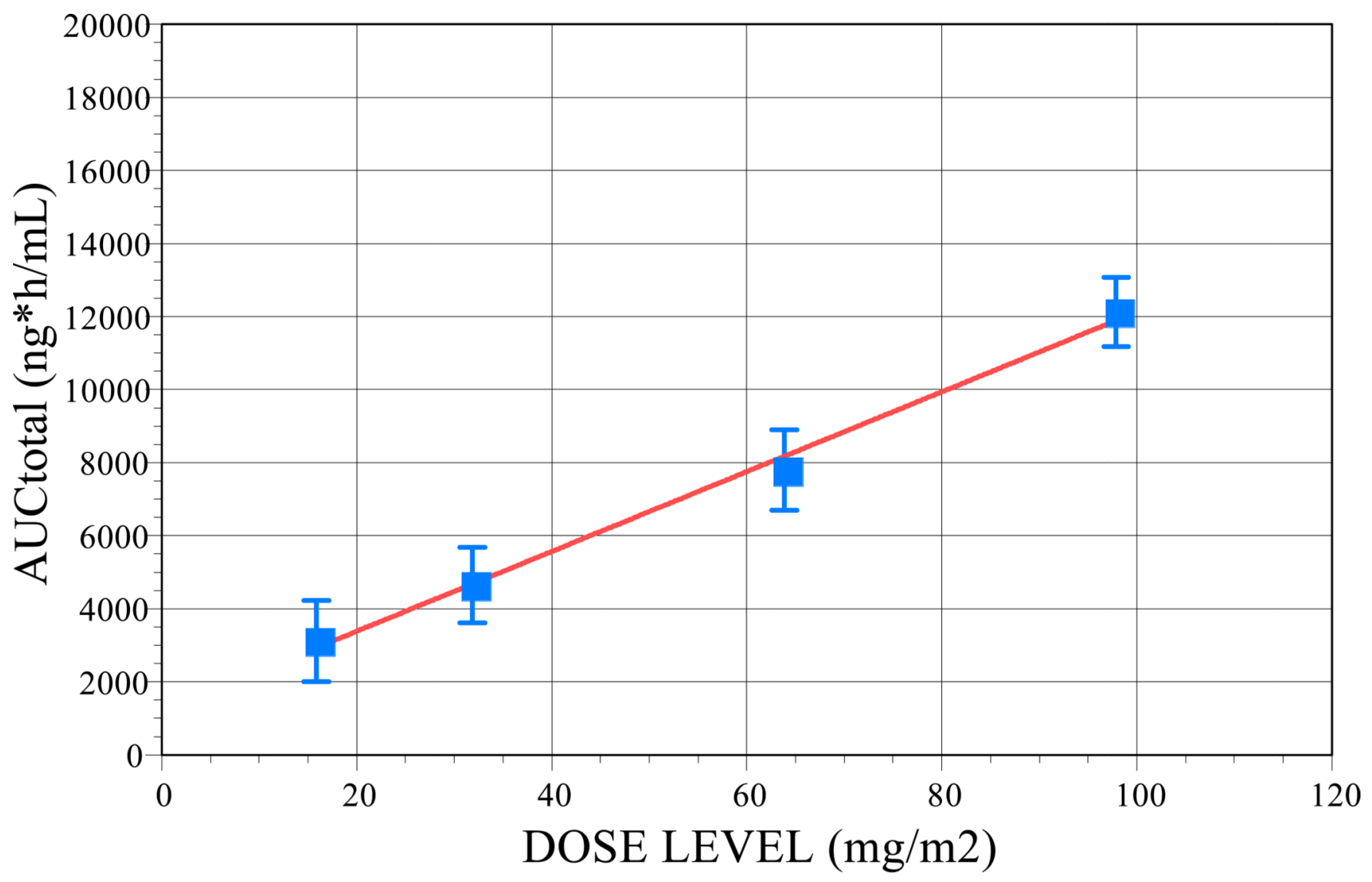

Linear $f(x)=1.09 E+2 * x+1.15 E+3 \quad R 2=0.995$

Figure 4. $\mathrm{AUC}_{\text {tot }}$ (Mean, sem) by dose levels, linear line of best fit through dose levels $16-100 \mathrm{mg} / \mathrm{m}^{2}$ 


\section{Table 1}

Patient Characteristics

\begin{tabular}{|c|c|c|}
\hline & $\begin{array}{l}\text { Schedule A } \\
(n=22)\end{array}$ & $\begin{array}{l}\text { Schedule B } \\
(n=10)\end{array}$ \\
\hline Gender (M:F) & $10: 12$ & $5: 5$ \\
\hline \multicolumn{3}{|l|}{ Age (years) } \\
\hline Median & 58 & 48 \\
\hline Ranges & $39-77$ & $25-69$ \\
\hline \multicolumn{3}{|l|}{ KPS } \\
\hline Median & 80 & 90 \\
\hline Ranges & $70-100$ & $80-90$ \\
\hline \multicolumn{3}{|l|}{ Tumor Type } \\
\hline Ovarian & 7 & 1 \\
\hline Colorectal & 5 & 1 \\
\hline NSCLC & 4 & 0 \\
\hline Lymphoma & 1 & 3 \\
\hline Other & 5 & 5 \\
\hline \multicolumn{3}{|l|}{ Number of Prior Regimens } \\
\hline Median & 5 & 5 \\
\hline Ranges & $2-9$ & $2-7$ \\
\hline Number of Prior Taxanes (\%) & $12(55 \%)$ & $5(50 \%)$ \\
\hline
\end{tabular}




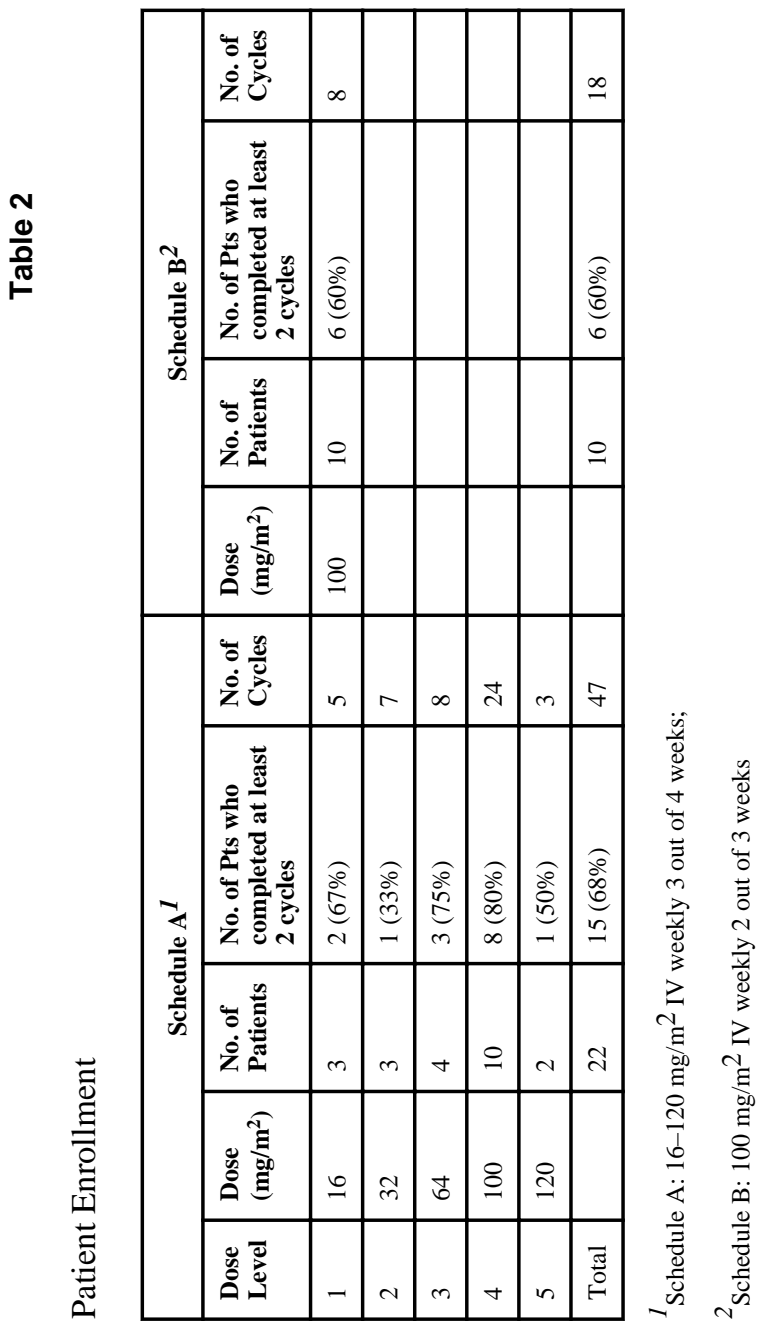

Invest New Drugs. Author manuscript; available in PMC 2014 April 29. 
